\title{
FEIRA DE SANTANA, LUGAR DE VIVÊNCIA - ELABORANDO MATERIAIS DIDÁTICO-PEDAGÓGICOS PARA O EJA (EDUCAÇÃO DE JOVENS E ADULTOS)
}

\author{
Mariana Oliveira de Jesús ${ }^{1}$; Cléa Cardoso da Rocha ${ }^{2}$. \\ 1. Bolsista FAPESB, Licenciatura em Geografia, Universidade Estadual de Feira de Santana, e-mail: \\ mariana.oliveira.js@gmail.com \\ 2. Orientadora, Departamento de Educação, Universidade Estadual de Feira de Santana, e-mail: \\ cleabase@yahoo.com.br
}

PALAVRAS - CHAVE: Lugar; Ensino de Geografia; Material Didático.

\section{INTRODUÇÃO}

O lugar é uma construção humana, que pode ser formado a partir da experiência que o indivíduo tem com determinado espaço, essa experiência pode se dar desde a sensação, percepção até o conhecimento conceitual que o indivíduo pode ter sobre o lugar (Tuan, 1983). A inserção deste conceito no ensino permite que a geografia passe a ter significado na vida dos alunos através da articulação entre lugar de vivência e os conteúdos. Assim, a elaboração de materiais didáticos com esse enfoque pode contribuir para essa articulação, pois, facilitam o processo de ensino e aprendizagem, materializam e exemplificam os conteúdos já que, considera-se que material didático pode ser impresso, digitalizado ou material audiovisual (som e imagem), desde que sejam voltados para fins pedagógicos podem ser considerados como material didático (Bandeira, 2009).

$\mathrm{Na}$ tentativa de contribuir com essa articulação propôs-se a presente pesquisa, que está vinculada ao projeto intitulado "Lugar, Formação Docente e elaboração de material didático sobre Feira de Santana" (SANTOS et.al., 2012). O desenvolvimento do estudo aqui apresentado deu-se em uma escola da rede estadual de Feira de Santana e no bairro Baraúnas, consistindo na elaboração e socialização de um material didático, vídeo documentário, sobre o Bairro Baraúnas, inicialmente destinado para Educação de Jovens e Adultos (EJA) procurando articular lugar de vivência aos conteúdos de geografia.

Com o desenvolvimento desta pesquisa buscou-se elaborar e disponibilizar para os alunos instrumentos para a compreensão da sua realidade, fortalecendo o conceito de lugar e, assim, auxiliar a que se tornem sujeitos ativos na sociedade. Acredita-se que fazer essa articulação, entre a vivência e os conteúdos de geografia, permite que os alunos possam ver o significado da geografia em sua vida, o que se torna premissa básica no ensino principalmente quando direcionados ao EJA.

\section{MATERIAL E MÉTODOS}

Para cumprir os objetivos propostos foram desenvolvidas as seguintes atividades: 1 . Recorte e Levantamento bibliográfico acerca dos conceitos-chave que basearam o desenvolvimento da pesquisa sendo: lugar; ensino de geografia e material didático; 2 . Participação quinzenal no grupo de estudos Lugar, com o objetivo de discutir os conceitos de lugar e material didático; 3. Identificação dos materiais disponíveis na escola para Educação de Jovens e Adultos no ensino de geografia; 4. Identificação do tema para elaboração do material didático; 5. Atividade de campo para: contatos iniciais com a comunidade, entrevistas com os moradores do bairro, observação das aulas na escola e socialização do material; 6.Análise e sistematização dos dados.7. Publicação dos resultados.

\section{RESULTADOS E DISCUSSÕES}

Percebe-se que o perfil dos alunos da EJA tem mudado muito ao longo do período de implantação do programa, no caso da escola campo investigada há uma grande diversidade na faixa etária dos alunos, o que se configura como dificuldade para o professor dar assistência e 
integrar uma turma tão diversificada. Observa-se ainda que essa mudança pode estar atrelada ao fato que muitos jovens, em idade regular que encontram-se nesta modalidade, já estarem inseridos no mercado de trabalho formal ou informal, como no caso da escola campo. A EJA é direcionada a pessoas que não concluíram ensino médio ou fundamental em idade regular, garantido por lei através do artigo 37 da lei $n^{\circ} 9.394$ de 20 de dezembro de 1996: "A educação de jovens e adultos será destinada àqueles que não tiveram acesso ou oportunidade de estudos no ensino fundamental e médio na idade própria” (BRASIL, 1996).

O planejamento para o ensino de geografia na modalidade de Ensino de Jovens e adultos nas classes acompanhadas na escola campo tem como principal objetivo discutir a importância do ensino de geografia para a compreensão do mundo em que vivemos. A partir da observação das aulas, percebeu-se que a professora em alguns momentos, como nas atividades, tenta fazer associações dos conteúdos com o lugar para facilitar a compreensão dos alunos, é interessante observar que os alunos também levam suas práticas cotidianas e utilizam como exemplo na sala de aula esclarecendo, a partir disso, as suas dúvidas. Um dos grandes desafios nas turmas de EJA, observado na escola campo, é a falta de oportunidades para participar dos projetos da escola, pois geralmente os alunos do noturno não são inseridos, muitas vezes por serem alunos que trabalham e pelos projetos não se estenderem ao turno da noite, excluindo parcialmente essa modalidade.

Compreendendo que os recursos audiovisuais contribuem significativamente para o ensino de geografia e tendo em vista que não foi encontrado material didático para o EJA semelhante e disponível na escola, escolheu-se elaborar um vídeo documentário que relacionasse geografia, lugar de vivência e meio ambiente. $\mathrm{O}$ vídeo, como recurso didático, facilita a compressão dos alunos, pois, apresenta os conteúdos de forma concreta principalmente por ser um material diferente do que é habitualmente utilizado na sala, o que poderia torna-se atrativo para os alunos ao unir imagem e som.

Para a elaboração do material didático proposto foram dados alguns passos como: atividade de campo no bairro Baraúnas, contatos iniciais com os moradores, visita a associação do bairro e entrevistas com os moradores.

A escolha do tema para o vídeo documentário está de acordo com o conteúdo do material didático que esta sendo elaborado para o projeto maior, sobre as Lagoas da cidade de Feira de Santana. Assim, utilizou-se para o vídeo o conteúdo de meio ambiente relacionado ao lugar e como área de estudo o bairro Baraúnas.

O bairro Baraúnas está localizado em Feira de Santana, próximo ao centro da cidade nas imediações da Avenida José Falcão, tendo em seu entorno o complexo de lagoas do Prato Raso e um dos corpos do complexo, a lagoa do Geladinho que tem sua área contida no Parque Erivaldo Cerqueira, conhecido como Parque da lagoa.

Inicialmente foram feitas entrevistas e filmagens com moradores mais velhos do bairro, que acompanharam as mudanças físicas e afetivas do lugar, com idade variando entre 30 e 70 anos. Dentre os entrevistados estão: professor, médico, carroceiro, líder comunitário, e a ex-parteira do bairro, na sua grande maioria os entrevistados residem no bairro desde que nasceram.

$\mathrm{Na}$ análise da fala dos moradores há diferentes percepções no que se refere ao bairro e sua transformação com o passar dos tempos, uns acreditam que a revitalização de uma parte da lagoa e as mudanças no bairro não tem aspectos positivos para a comunidade, porém apesar dessa percepção o sentimento de pertencimento é comum entre todos os moradores que foram entrevistados. A partir da experiência, da percepção do vivido, os moradores fazem a construção afetiva do recorte espacial, através das formas de uso que fazem do lugar através das manifestações culturais como enterro do ano e marcha para Jesus e a utilização da área da lagoa para reunir amigos e familiares. 
Na tentativa de compreender esses posicionamentos recorremos a Tuan (1983), este nos traz que há diferentes formas subjetivas de se ter experiências no espaço, podendo ser através da visão, percepção, sensação, tato e conhecimento conceitual, observa ainda que as pessoas podem ter relações com o seu lugar através das diferentes formas de experiência que os indivíduos têm.

Assim, através das gravações das entrevistas foi elaborado o vídeo documentário, material didático proposto, que teve como objetivo contribuir para a construção do conceito de lugar de maneira a possibilitar aos alunos a significação da geografia para sua realidade.

Para analisar a utilização do material na sala de aula, o vídeo-documentário "Baraúnas que lugar é esse?", foi exibido para duas turmas de EJA da escola campo, tendo como espectadores 44 alunos e quatro professores, além da equipe da pesquisa, observa-se que o vídeo apresentado foi um piloto do documentário, que está fase de pós-produção. Os espectadores foram convidados a avaliar o material através de um questionário, aplicado após assistirem ao vídeo documentário. As questões versavam desde a linguagem utilizada no vídeo ao entendimento do conceito de lugar e as relações que faziam a respeito do seu cotidiano após assistirem ao vídeo.

Os quatro professores de geografia que assistiram consideraram que o material tem uma linguagem fácil e acessível ao estudante, dois deles avaliaram o vídeo como bom e dois como ótimo. Todos afirmaram que utilizariam o material didático elaborado nas suas aulas de geografia, além de afirmarem acreditar que o vídeo contribuiu na construção de novos conhecimentos geográficos pelos alunos, justificando que influencia a ideia de lugar e de pertencimento e auxilia à motivação dos alunos ao estudo da geografia. Dois professores afirmaram ser necessária a inserção de imagens dos projetos e manifestações culturais realizadas no bairro, o que está sendo providenciado.

$\mathrm{Na}$ avaliação dos alunos, quando perguntados sobre o que mudou no seu entendimento em relação ao conceito de lugar depois de ter assistido ao vídeo, os alunos responderam que até então não conheciam o bairro e o vídeo estimulou a conhecer, principalmente por ser um bairro considerado ruim e perigoso na cidade e, treze alunos afirmaram que a concepção de lugar não mudou depois de ter assistido ao documentário. De modo geral, os alunos fizeram uma avaliação positiva do vídeo (Gráfico 01)

Sobre o que entendem por lugar os alunos responderam que lugar é onde moramos, nos sentimos bem e onde nos relacionamos com outras pessoas podendo ser algo que pode se estender a outros locais, apenas um aluno considera o lugar como uma localização. Os alunos citaram alguns aspectos como sugestões para melhorar o vídeo documentário como é apresentado no Gráfico 2.

Assim, consideramos as sugestões dos alunos como relevantes para o material didático já que, eles são os sujeitos do processo de ensino, as sugestões foram consideradas para ajustes no vídeo documentário. 

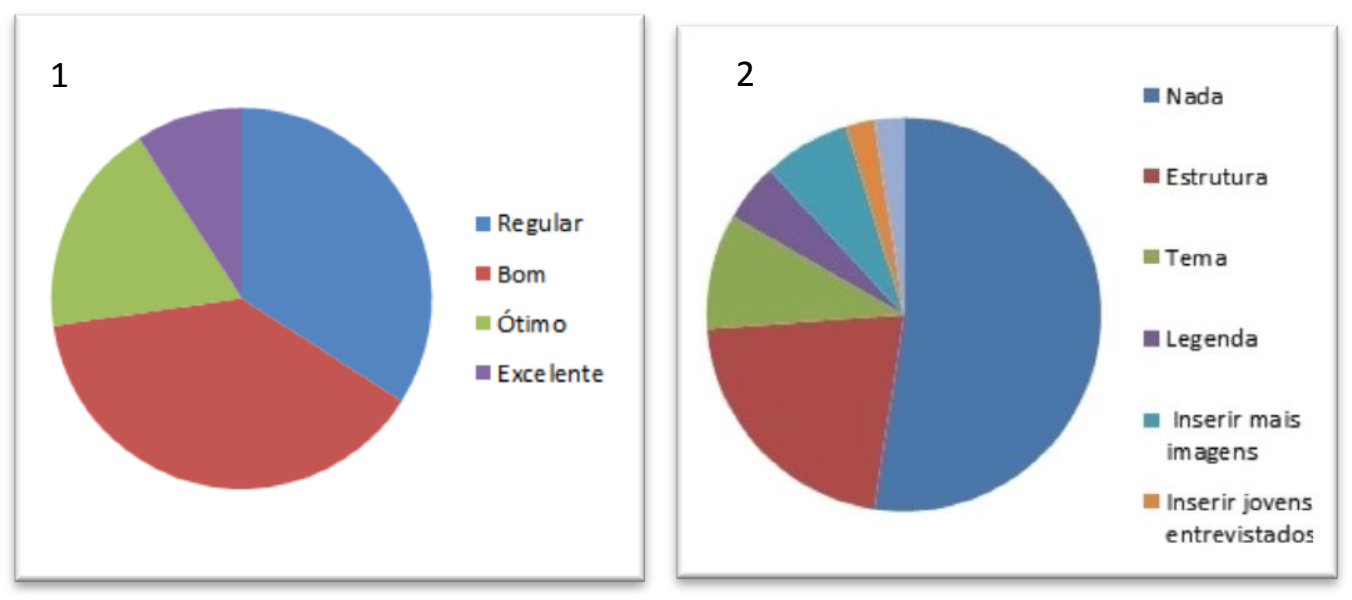

Gráfico 1: Como os alunos consideraram o vídeo. Gráfico 2: Sugestões dos alunos para o vídeo

\section{CONSIDERAÇÕES FINAIS}

É necessário repensar os planejamentos para o EJA e criar alternativas que motivem os alunos a compreenderem o significado da geografia na sua vida, trazendo essa relação de forma efetiva já que se trata de alunos trabalhadores e que são excluídos em parte dos projetos da escola, assim, a elaboração do vídeo documentário, traz para o EJA um novo recurso didático relevante, pois o material aborda o lugar articulado com os conteúdos de geografia. Assim, o vídeo contribuiu para a percepção dos alunos sobre o lugar e também para o grupo de pesquisadores, visto que nas entrevistas para a elaboração do material didático com os moradores do bairro Baraúnas percebeu-se que os moradores falam da sua experiência com o lugar vivido, do experienciado, do concreto e vão até a percepção do lugar sagrado, da questão do pertencimento mútuo entre o ser, os lugares e utensílios ao seu redor. Assim, a partir da análise e avaliação do vídeo feita pelos alunos e professores percebeu-se que a utilização desse material nas aulas de geografia destaca a sua contribuição ao ensino ressaltando a articulação do lugar de vivência aos conteúdos o que pode propiciar que a geografia tenha significado na vida dos alunos.

\section{REFERÊNCIAS}

BANDEIRA, Denise. Material didático: conceito, classificação geral e aspectos da elaboração. In: CIFFONE, H (org.). Curso de Materiais didáticos para smartphone e tablete. Curitiba, IESDE, 2009, p. 13-33. Disponível em: http://www2.videolivraria.com.br/pdfs/24136.pdf. Acesso em: 17.10.2016

BRASIL. Ministério de Educação e Cultura. LDB Lei no 9394/96, de 20 de dezembro de 1996. Estabelece as Diretrizes e Bases da Educação Nacional. Brasília: MEC, 1996.

SANTOS, Célia Regina et.al.; Lugar, formação docente e elaboração de material didáticopedagógico sobre feira de Santana/BA. Universidade Estadual de Feira de Santana, 2012. TUAN, Yu-Fu. Espaço e Lugar: A perspectiva da experiência. São Paulo: DIFEL, 1983. 